DOI https://doi.org/10.30525/978-9934-588-86-0.06

\title{
OPTIMIZATION OF THE RESERVATION LEVEL OF MACHINES OF PORT TRANSHIPMENT COMPLEXES
}

\author{
Zubko M. F., Nemchuk O. O.
}

\section{INTRODUCTION}

Modern machines of port transshipment complexes, as a rule, have automated systems of protection against damage of separate blocks, mechanisms and the machine as a whole at their technological use and influence of external factors, systems of technical diagnostics and registration of a current technical condition of the machine work. The value of the relevant indicators and characteristics in the required amount is supplied to the appropriate user for practical use. As a result, automated systems for collecting and processing statistical information on the reliability of machines and the results of their technological use are created in ports. Unfortunately, the structure of this information is adapted mainly to assess the quality of machines and their operation based on the results of the past period.

Insufficient attention is paid to the practical tasks of forecasting the quality of technological and technical operation of machines. The presence of such tasks in the information system gives the user the final materials for the rapid adoption of the most profitable options for planning the technological use of machines for the intended operating conditions. Solutions of separate problems of this class in part of optimization of level of reservation of group of identical machines are considered in the given work.

\section{FORECAST OF RELIABILITY AND OPERATIONAL CONDITIONS OF MACHINES}

In the general case, specialized transshipment complexes of seaports consist of four main groups of machines: mooring machines, warehousing machines, land transport machines and machines within the terminal cargo transportation. In modern complexes, each of these groups consists of the same type of machine, often of the same model, which in terms of technical parameters and, in the stationary period of operation, the reliability is the same. Therefore, in this problem we consider a system of sliding redundancy, consisting of identical machines with recovery in the stationary period of operation. The general scheme of functioning of such system is given in Fig. 1.

The system consists of $\mathrm{N}=\mathrm{n}+\mathrm{m}+\mathrm{s}$ elements, of which $\mathrm{n}$ elements are the main, $\mathrm{m}$ is the loaded reserve, and s elements are the unloaded reserve. The system also includes a repair service with $\mathrm{r}$ repair posts. One post can only restore one item at a time. 


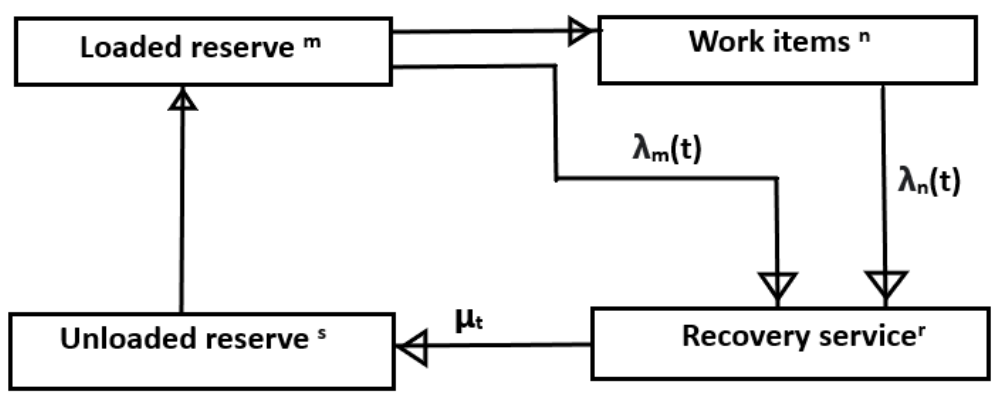

Fig. 1. Estimated scheme of sliding redundancy system with recovery

We accept that failures of elements are found out instantly and the failed element is at once transferred to the repair service. If there are free repair places, the recovery of the element begins without delay. Otherwise, the item becomes queued. All posts can work simultaneously, i.e. several elements can be restored simultaneously.

If the main element fails, its place is taken by the element from the loaded reserve. Elements dropped from the loaded reserve are replaced by elements from the light reserve, and the latter in turn - from the unloaded reserve. Restored items from the repair service come only to the unloaded reserve. The ways of successive movements of elements are marked with arrows in Fig. 1.

We will assume that all elements in the system are independent in terms of reliability and intensity of their failures depend only on the situation in the system of work - reserve - recovery. The switches for the transition of elements from one group to another are absolutely reliable. Transitions happen almost instantly. The probability of failure of two or more elements at the same time is very small. Restoration is performed to the initial technical condition of the element (the reliability functions of the elements after restoration do not change). As can be seen from the diagram in Fig.1, the total failure rate of elements in the system is:

$$
\lambda_{c}(t)=\lambda_{n}(t)+\lambda_{m}(t)
$$

where $\lambda_{n}(t), \lambda_{m}(t),-$ failure rates, respectively, the group of basic elements and elements of the loaded reserve.

The intensity of failures $\lambda_{c}(t)$ and the intensity of element recovery $\mu_{c}(t)$ determine the number of elements $n_{k}$ which at the time of operation $t$ are in a state of failure (did not have time to recover). It is obvious that the considered system remains operational as long as the number of elements that are simultaneously in a state of failure does not exceed the number of spare elements, i.e. until $n_{k} \leq m+s$.

The system failure will occur at the time of operation, when:

$$
n_{k}^{0}=N-n+1 \text {. }
$$


Therefore, the probability of failure of the system for the operating time $t$ is

$$
\bar{F}_{c}(t)=1-P_{N-n+1}(t),
$$

where $P_{N-n+l}(t)$ - the probability of occurrence of $N-n+1$ elements in a state of failure during operation $t$.

We introduce some additional notation. In the process of use, the system can go into different states characterized by the number of inoperable elements. Let's say that the system is in a state $k$, if there are $k$ elements in a state of failure at the considered moment of work. Obviously, the system can be in each of the states $k=0,1,2, \ldots, N$, if we assume that the failure of the system occurs when all elements fail. Let's mark $\lambda_{k}(t)$ - the intensity of the transitions of the system to the state $k$, equal to the total failure rate of the elements; $\mu_{k}(t)$ - the total intensity of recovery of elements, i.e. the intensity of transitions from state $k$ to state $k-1$.

The probability of the system being in the state $\mathrm{k}$ in the stationary period of its operation $p_{k}$ is called the limiting or final probability. Physically, $p_{k}$ means the average share of operating time during which the system is in state $\mathrm{k}$ when reaching a stationary period of operation.

The value of the final probabilities is from the relations:

$$
p_{k}=\beta_{k} / \sum_{k=0}^{N} \beta_{k},
$$

where

$$
\beta_{k}=\frac{\lambda_{0} \lambda_{1} \lambda_{2} \lambda_{k-1}}{\mu_{1} \mu_{2} \mu_{k}} ; \beta_{0}=1
$$

Here $\mu_{k}$ and $\lambda_{k}$ are the intensities of failure and recovery flows in the $k-$ state of the system.

Obviously that

$$
\sum_{k=0}^{N} p_{k}=1
$$

At parameters of exponential distributions of operating time on failure of any element $\lambda$ and time of its restoration by one repair post $\mu$ according to streams of failures and restoration of the settlement scheme in Fig.1 we have: 


$$
\begin{aligned}
& \lambda_{k}=\left\{\begin{array}{lc}
(N-s) \lambda, & 0 \leq k \leq s ; \\
(N-k) \lambda, & s<k \leq N ;
\end{array}\right\} \\
& \mu_{k}=\left\{\begin{array}{ll}
k \mu, & k<r ; \\
r \mu, & k \geq r .
\end{array}\right\}
\end{aligned}
$$

Substituting sequentially the values of $\lambda_{k}$ and $\mu_{k}$ from formula (7) in formula (5) we find:

$$
\beta_{k}=\left\{\begin{array}{lc}
\frac{(N-s)^{k} \gamma^{k}}{k !}, & 0 \leq k \leq s, s \leq r ; \\
\frac{(N-s)^{s} \gamma^{k}}{k !} \prod_{j=1}^{k-s}(N-s+1), & s<k \leq r ; \\
\frac{(N-s)^{k} \gamma^{k}}{r ! r^{k-r}}, & r<k \leq s ; \\
\frac{(N-s)^{s} \gamma^{k}}{r ! r^{k-r}} \prod_{j=1}^{k-s}(N-s+1), & r<k \leq N, s \leq r,
\end{array}\right\},
$$

where $\gamma=\lambda / \mu$, or $\gamma=\frac{1}{K_{\Gamma}}-1$, if there is only a statistical value of the readiness factor of one machine.

The average operating time of the system to failure in the stationary period of operation ${ }^{1}$ :is:

$$
T_{o c}=\frac{1}{\lambda_{N-n} p_{N-n}} \sum_{k=0}^{N-n} p_{k}
$$

The probability of trouble-free operation of the system in the stationary period of operation is:

$$
P_{o c}(t)=e^{-\frac{t}{T_{0 c}}}
$$

${ }^{1}$ Zubko N. F. Nadyozhnost i planirovanie ekspluatatsii mashin: Uchebnoe posobie dlya VUZov. Odessa: ONMU. 2013. 279 s. 
The system readiness factor is:

$$
K_{\Gamma C}:=\sum_{k=0}^{N-n} p_{k}
$$

The average system recovery time is:

$$
T_{B C}=\frac{1}{\lambda_{N-n} p_{N-n}}\left(\sum_{k=N-n+1}^{N} p_{k}\right) .
$$

The average number of occupied repair posts is:

$$
n_{3 p}=\sum_{k=0}^{r} k p_{k}+r\left(\sum_{k=r+1}^{N} p_{k}\right) \text {. }
$$

The average number of items in the service queue is:

$$
n_{\text {ou }}=\sum_{k=r+1}^{N}(k-r) p_{k} .
$$

Let's give the coefficients of use of the elements of the system the following ratios:

$$
K_{t}=t_{1} / t_{0}, K_{e}=t_{e} / t_{0}, K_{6}=t_{b} / t_{0}, K_{p}=t_{p} / t_{0},
$$

where $t_{t}$ is the average residence time of the element in working condition on the main object; $t_{u}$ - the average waiting time of the item in the queue for recovery; $t_{p}$ - the average recovery time of the element; tp is the average residence time of the element in the reserve.

The total average service life of the item on the site is:

$$
\mathrm{t}_{0}=\mathrm{t}_{\mathrm{t}}+\mathrm{t}_{\mathrm{e}}+\mathrm{t}_{\mathrm{B}}+\mathrm{t}_{\mathrm{p}} \text {. }
$$

Under these conditions, the corresponding coefficients are equal to ${ }^{2}$ :

The machine utilization rate on the main object is:

${ }^{2}$ Nadezhnost tehnicheskih sistem: Spravochnik / Yu. K. Belyaev, V. A. Bogatyirev, V. V. Bolotin i dr.; Pod red. I. A. Ushakova. Moskva: Radio i svyaz, 1985. 608 s., S. 43-45. 


$$
K_{t}=\frac{n}{N} \sum_{k=0}^{N-n} p_{k}+\sum_{k=N-n+1}^{N}\left(1-\frac{k}{N}\right) p_{k}
$$

The ratio of the machine in the queue for recovery is:

$$
K_{u}=\frac{1}{N} \sum_{k=r+1}^{N}(k-r) p_{k} \text {. }
$$

The coefficient of stay of the machine on restoration is:

$$
K_{B}=\frac{1}{N}\left[\sum_{k=0}^{r} k p_{k}+r\left(1-\sum_{k=0}^{r} p_{k}\right)\right] .
$$

The coefficient of stay of the machine in a reserve is:

$$
K_{p}=\sum_{k=0}^{N-n}\left(1-\frac{n+k}{N}\right) p_{k} .
$$

Analyzing the values of these coefficients, we can assess the effectiveness of the structure of the system "fleet - repair base" with a known reliability of the elements and the capacity of the repair base. For example, a high value of the coefficient $K_{u}$ indicates insufficient capacity of the repair base, the coefficient $K_{p}$ - an excess reserve.

\section{Example of calculation 1.}

Output data. Portal cranes are used for unloading vessels at berths of the bulk cargo complex with an annual turnover of $\boldsymbol{Q}=45$ million tons. All cranes have the same technical characteristics, they are in the stationary period of operation and are identical or close enough in terms of reliability, i.e. the distribution of their operating time to failure and recovery time can be taken exponentially. The distribution parameters, respectively, $\lambda=0,007$ and $\mu=0,1$. That is, the average failure time of the crane $T_{0}=150 \mathrm{mg}$ and the average recovery time $T_{b}=10 \mathrm{~h}$, while the coefficient of readiness of the crane $K_{\Gamma}=0.938$.

The technological productivity of one crane is $q=650 \mathrm{t} / \mathrm{h}$.

The normative total time of ship unloading works at the specified cargo turnover is $T_{H}=7000 \mathrm{~h}$, i.e. the minimum necessary quantity of continuously working machines for performance of the set volume of work for normative time is:

$$
n=\frac{Q}{K_{\Gamma} T_{H} q}=\frac{45000000}{0.938 \cdot 7000 \cdot 650}=10,549
$$


We accept the number of working machines $n=11$ units.

To ensure the reliability of the implementation of the normative value of the TN provides for the reservation of a group of cranes in the machines of the loaded reserve $m=2$ units and one machine of the unloaded reserve $s=2$ units. The number of repair posts is taken $r=2$ posts.

The total number of planned cranes for the mooring group:

$N=n+m+s=11+2+3=15$ units

\section{The results of the calculation}

For the given conditions of the technological use and parameters of the group of machines as a redundant recovery system, we calculate the main indicators of its reliability and the coefficients of operational states of the components of the machines.

The calculations were performed in the Mathcad program.

The final probabilities of system states (4):

$$
\begin{gathered}
p_{0}=0.389, p_{1}=0.337, p_{2}=0.146, \ldots p_{15}=7.273 \times 10^{-6} . \\
\sum_{k=0}^{N} p_{k}=1
\end{gathered}
$$

Condition (6) is met.

The system readiness factor is $(2.11)$ :

$$
K_{\Gamma C}:=\sum_{k=0}^{N-n} p(k) \quad K_{\Gamma C}=0.89 .
$$

The average operating time of the system to failure in the stationary period of operation is (9): $T_{o c}=84,441 \mathrm{~m}-\mathrm{g}$.

The average system recovery time is (12): $T_{b c}=10,427$ hours.

Checking the consistency of the coefficients of readiness of the system calculated by the formula (2.11) and the values of the average operating time of the system to failure $T_{o c}$ and the average recovery time of the system $T_{b c}$ :

$$
K_{\Gamma C}=\frac{T_{o c}}{T_{o c}+T_{B c}}=\frac{416.7}{416.7+11.9}=0.972
$$

The results of the calculations are given in table. 2.1, they indicate a fairly high reliability of the crane system, as its coefficient of readiness is $K_{\Gamma C}=0.89$.

The average overload time of a given load $T_{\partial}=6474 \mathrm{~m}-\mathrm{h}(22)$.

That is $T_{\partial}<T_{H}$. The planned cargo turnover will be performed in a timely manner.

The main results of the calculations are given in table 1 and table. 2 . 
The system has a fairly high coefficient of stay of a single machine in operation on the main object $K_{t}=0.73$. Recovery of machines after failure is performed soon enough, so there is almost no queue for recovery, and the coefficient of stay of the machine on recovery $K_{b}=0,059$. The average number of occupied repair posts $r_{3 p}=0.88$, i.e. it is possible to plan 1 repair post. In general, the considered option of reserving the crane group can be recommended for practical use. However, the relatively long recovery time of the $T_{b c}$ system $=11.9$ hours is questionable. Therefore it is necessary to carry out optimization of structure of technical equipment of a complex on criterion of a maximum of profit following the results of performance of planned work.

Table 1

General performance of the system

\begin{tabular}{|l|c|c|}
\hline \multicolumn{1}{|c|}{ Characteristic } & Symbol & Value \\
\hline The average operating time of the system to failure & $T_{o c}$ & $416.7 \mathrm{~m}-\mathrm{g}$ \\
\hline The average system recovery time & $T_{B c}$ & 11,9 hours \\
\hline The system readiness factor & $K_{\Gamma C}$ & 0.972 \\
\hline The average number of occupied repair posts & $n_{3 p}$ & 0.88 units \\
\hline The average number of machines in line for repair & $n_{u}$ & 0.24 units \\
\hline
\end{tabular}

Table 2

Coefficients of stay of the machine in operational states

\begin{tabular}{|c|l|c|c|}
\hline $\begin{array}{c}\text { № } \\
\text { para. }\end{array}$ & \multicolumn{1}{|c|}{ Characteristic } & Symbol & Value \\
\hline 1 & Works of the machine on the main object & $K_{t}$ & 0.73 \\
\hline 2 & The machine is in line for recovery & $K_{u}$ & 0.016 \\
\hline 3 & Stay of the machine on restoration & $K_{b}$ & 0.059 \\
\hline 4 & The machine is in reserve & $K_{p}$ & 0.195 \\
\hline 5 & $\begin{array}{l}\text { Checking the consistency of the coefficients by the } \\
\text { amount }\end{array}$ & $\sum K$ & 1 \\
\hline
\end{tabular}

\section{OPTIMIZATION OF THE REDUNDANCY LEVEL OF THE RECOVERY GROUP OF IDENTICAL MACHINES}

As a criterion for the optimality of the problem, it is advisable to take the profit $\mathrm{P}$ obtained as a result of the planned task. In this case, we will take into account only the income and expenses that occur directly in the process of reloading. The absence of costs for spare parts, maintenance, repairs and other deductions does not affect this part of the income when using the crane. Under these conditions, the criterion of optimality has the form:

$$
\max H=\max \left(H_{O B}+H_{T}+H_{R m}-R_{R s}-R_{B O}-R_{R P}-R_{O}\right) .
$$


The indicators taken into account in formula (22) are given in table. 3. The numerical values of indicators are defined in US dollars (USD).

Given the average operating time of the system for the period of execution of the planned volume of work TD according to the formula (22), the profit on the results of work on the main object is:

$$
H_{O B}=n\left(c_{2}-c_{e}\right) T_{\partial}
$$

Table 3

Indicators in the optimality criterion

\begin{tabular}{|c|c|l|c|}
\hline $\begin{array}{c}\text { № } \\
\text { para. }\end{array}$ & symbol & Name & Value \\
\hline 1 & $c_{2}$ & Tariff rate for one ton of cargo transshipment. & 5 \\
\hline 2 & $c_{e}$ & $\begin{array}{l}\text { Total operating costs per 1 m-h of machine operation at the main } \\
\text { facility. }\end{array}$ & 100 \\
\hline 3 & $c_{n}$ & $\begin{array}{l}\text { Award for 1 hour reduction of time of performance of the planned } \\
\text { task concerning normative value. }\end{array}$ & 1200 \\
\hline 4 & $c_{u}$ & Penalty for 1 hour of exceeding the standard time. & 2400 \\
\hline 5 & $c_{\partial p}$ & Income for 1 hour of machine operation in the loaded reserve. & 300 \\
\hline 6 & $c_{e p}$ & $\begin{array}{l}\text { Total operating costs attributed to 1 m-h of machine operation in } \\
\text { the loaded reserve. }\end{array}$ & 100 \\
\hline 7 & $c_{\mu p}$ & Losses for 1 hour of machine downtime in unloaded reserve. & 100 \\
\hline 8 & $c_{b}$ & $\begin{array}{l}\text { Total costs attributed to 1 hour of restoration of the machine after } \\
\text { failure. }\end{array}$ & 500 \\
\hline 9 & $c_{\mu p}$ & Total costs attributed to 1 hour of the maintenance post. & 50 \\
\hline
\end{tabular}

The profit (loss) depending on the time of execution of planned works is:

$$
H_{T}= \begin{cases}\left(T_{H}-T_{\partial}\right) c_{n}, & T_{\partial}<T_{H} ; \\ \left(T_{H}-T_{\partial}\right) c_{u}, & T_{\partial}>T_{H} .\end{cases}
$$

The profit when using machines in the loaded reserve is:

$$
H_{R m}=\left(c_{\partial p}-c_{\ni p}\right) m K_{P} T_{0} C
$$

The costs when machines are in the unloaded reserve are:

$$
R_{R S}=c_{\mu p} s K_{P} T_{0} C
$$

The costs for restoration of machines after failure are:

$$
R_{R S}=c_{\mu p} s K_{P} T_{0} C
$$


The costs for maintenance of the unused posts are:

$$
R_{R P}=c_{p n}\left(r-n_{3 p}\right) K_{P} T_{0} C
$$

The costs due to the queue for the restoration of machines after failure are:

$$
R_{O}=0,5 C_{e} n_{o u} K_{e} T_{0} C
$$

\section{Example of calculations 2.}

Output data. For the conditions of example 1 to determine the optimal level of loaded $m$ and unloaded $s$ reserves, as well as the optimal number of repair posts $r$ by the criterion of profit (23) due to the planned task.

The solution of the problem was carried out in the Mathcad program by a method of comparison of indicators of the basic from possible variants of the organization of technological use of the parking place of machines. The consequences of the calculations are given in table 3 .

The best options from the considered are options 4 and 5, which have a fairly large profit, 1.4 times the profit when using an unserviced group of machines. The advantage of option 4 is a small level of redundancy, the disadvantage is that the time of the planned work is $1 \%$ longer than the standard term. Option 5 provides a shorter period of work (possible premium), but requires an additional machine loaded reserve. Obviously, these factors should be considered when determining the best option.

Table 4

The results of profit calculations based on the results of the system

\begin{tabular}{|c|c|c|c|c|}
\hline $\begin{array}{c}\text { № } \\
\text { para. }\end{array}$ & Reservation level & $\begin{array}{c}\text { Profit, million } \\
\text { USD }\end{array}$ & $K_{\Gamma C}$ & Shiphours \\
\hline 1 & $\mathrm{~m}=0, \mathrm{~s}=0, \mathrm{r}=1$ & 155,6 & 0,215 & 29310 \\
\hline 2 & $\mathrm{~m}=1, \mathrm{~s}=0, \mathrm{r}=1$ & 177,3 & 0,295 & 21350 \\
\hline 3 & $\mathrm{~m}=1, \mathrm{~s}=1, \mathrm{r}=1$ & 195,3 & 0,411 & 15310 \\
\hline 4 & $\mathrm{~m}=1, \mathrm{~s}=1, \mathrm{r}=2$ & 220,8 & 0,89 & 7071 \\
\hline 5 & $\mathrm{~m}=2, \mathrm{~s}=1, \mathrm{r}=2$ & 221,5 & 0,937 & 6716 \\
\hline 6 & $\mathrm{~m}=2, \mathrm{~s}=2, \mathrm{r}=2$ & 222 & 0,972 & 6474 \\
\hline 7 & $\mathrm{~m}=2, \mathrm{~s}=2, \mathrm{r}=3$ & 222 & 0,993 & 6337 \\
\hline
\end{tabular}

The solution of the problem was carried out in the Mathcad program by a method of comparison of indicators of the basic from possible variants of the organization of technological use of the parking place of machines.

The best options from the considered are options 4 and 5, which have a fairly large profit, 1.4 times the profit when using an unserviced group of 
machines. The advantage of option 4 is a small level of redundancy, the disadvantage is that the time of execution of planned work is $1 \%$ longer than the normative term, which can cause penalties. Option 5 provides a shorter lead time, i.e. a possible premium, but requires an additional machine loaded reserve. Obviously, these factors should be considered when determining the best option.

\section{OPTIMIZATION OF THE LEVEL OF OPERATIONAL RESERVE OF THE GROUP OF NON-RENEWABLE MACHINES}

The task of the operational reserve of machines is to ensure the guaranteed implementation of the planned volume of work during the estimated time $T_{p}$. This time must be significantly less than the average operating time before the failure of $T_{n, m}$ of the main and backup groups of machines as a single system, i.e. the condition $T_{p}<T_{n}, m$. Otherwise, the probability of fulfilling the planned task will be small.

The first case. Loaded reserve. A system consisting of $\mathrm{N}=\mathrm{n}+\mathrm{m}$ working elements is considered. The part of elements $\mathrm{n}$ is used for technological maintenance of the main object. The remaining m elements serve as secondary objects and are planned as a loaded reserve for the main object. The technological maintenance of all objects is carried out by identical interchangeable machines. It is assumed that the performance of all machines of the system in the maintenance of the main object is the same.

An example of such a system is the transshipment complex of the seaport using gantry cranes. Here the main object is a vessel under cargo operations. The less important objects are land vehicles and warehouses located in the working area of cranes. The cost of parking time for land vehicles is significantly less than ships. If necessary, freight machines can be quickly redirected to other parts of the complex. Warehouse sorting work is usually permissible to shift in time.

The need to determine the optimal or at least economically feasible level of redundancy arises in the process of planning the use of existing fleet of vehicles at several sites, taking into account the possibility of decommissioning of machines to perform scheduled maintenance and repairs, lease and other circumstances. Thus the planned volume of work on the main object $\mathrm{Q}=$ quantity of cargo on the vessel, the standard time of parking of the vessel under cargo operations, $T_{H} h$ and the technological productivity of one machine $\mathrm{q}(\mathrm{t} / \mathrm{h})$ are set. It is assumed that the time of replacement of the machine that failed in the process of servicing the main object, any of the same type of working machines employed at a less significant object is quite small relatively to the standard time of technological processing of the object. Machines of the loaded reserve can refuse earlier than machines occupied on the main object. Failed machines usually cannot be repaired for the rest of the 
time until the main facility is completed. Therefore, in relation to the main object, the considered system is not renewable.

The minimum required number of machines for technological processing of the main object is determined by formula (19), bearing in mind that the coefficient of readiness of the non-renewable system is $K_{\Gamma C}=1$.

The actual time of trouble-free operation of the system when working on object $T_{\partial}$ may be, depending on the reliability of the machines and the level of redundancy, greater or less than the standard time of the vessel under cargo operations $T_{H}$.

Under the above conditions, the problem is to optimize the operation of a non-renewable system with a sliding reserve, which includes $n$ main and $m$ elements of the loaded reserve. The functions of the distribution of the operating time of the elements to failure $F(t)$ are known. We assume that all elements are independent of each other in terms of reliability and the probability of failure of two or more elements simultaneously is an infinitesimal value.

Based on the need to perform the planned task for the standard time, the failure of the redundant system is an event when $k<n$ working elements appear, i.e. the system failure occurs after the occurrence of $m+1$ failure of the total number of spare elements. The probability of failure-free operation of such a system during operation $t$ is determined by the sum ${ }^{3}$ :

$$
\bar{F}_{n, m}(t)=\sum_{k=n+m}^{n} \bar{F}_{k}(t)
$$

where $\bar{F}_{k}(t)$ - the probability that there are exactly $k$ working elements at the time of implementation of the operating time $t$ in the system.

In the presence of fines and bonuses depending on the actual time of implementation of the planned task, the criterion for the optimal level of the system redundancy is still the maximum profit received during the processing of the main object (23) with the exception of components related to unloaded reserve and recovery of machines after failures. In the expanded form, the criterion of optimality has the equation:

$$
\begin{gathered}
\max H=\max \left(T\left(n_{2}-c_{\epsilon}\right) c_{\partial}+\left\{\begin{array}{ll}
\left(T_{H}-T_{\partial}\right) c_{n}, & T_{\partial}<T_{H} \\
\left(T_{H}-T_{\partial}\right) c_{u}, & T_{\partial}>T_{H}
\end{array}\right\}+\right. \\
+\left(c_{\partial p}-c_{\ni p}\right) T_{m p}
\end{gathered}
$$

${ }^{3}$ Zubko N. F. Nadyozhnost i planirovanie ekspluatatsii mashin: Uchebnoe posobie dlya VUZov. Odessa : ONMU, 2013. 279 s. 128 s. 
The total time spent by the reserve machines in the reserve state:

$$
T_{m p}(m)=m T_{n}(0)+(m-1)\left[T_{n}(1)-T_{n}(0)\right]+(m-2)\left[T_{n}(2)-T_{n}(1)\right]+\ldots
$$

Or in the expanded form at $\mathrm{m}>1$ :

$$
T_{c m}(m)=m T_{n}(0)+\sum_{i=1}^{m-1}(m-i)\left[T_{n}(i)-T_{n}(i-1)\right]
$$

where

$$
T_{n}(i)=\int_{0}^{T_{p}} \bar{F}_{n, i}(t) d t
$$

The actual value of the time of reloading work on the main object is determined from the condition:

$$
\bar{F}_{n m}\left(t_{\partial}\right)=0,9 \text {. }
$$

That is, the probability of realization of the calculated operating time $T_{\partial}$ should be not less than 0.9 .

In the presence of a technological restriction on the number of working machines $n$ occupied on the main object, the varied parameter in the process of determining max $H$ from equation (32) is the number of spare machines $m$.

Solving the problem requires the presence in the form of an analytical dependence on the development of the reliability function of the redundant system. Unfortunately, the analytical form of the function (24) is very cumbersome and inconvenient to use. Usually this dependence is used only in the presence of numerical values $\bar{F}_{n m}\left(T_{\partial}\right)$ of the function for all possible combinations of $n$ and $m$.

This problem considers a redundant system in which all the main and backup machines are independent in terms of reliability and have the same function of the distribution of operating time to failure $F_{o}(t)$.

Under these conditions, the reliability function of the redundant system in the general case is determined by the formula ${ }^{4}$ :

$$
\bar{F}_{n, m}(t)=\sum_{k=0}^{m} \frac{(n+m) !}{k !(n+m-k) !}\left[F_{0}(t)\right]^{k}\left[\bar{F}_{0}(t)\right]^{(n+m-k)}
$$

By formula (36) it is easy to calculate if numerical values $\bar{F}_{n, m}(t)$ of the reliability of the components are known. Determining the main characteristics

${ }^{4}$ Zubko N. F. Nadyozhnost i planirovanie ekspluatatsii mashin: Uchebnoe posobie dlya VUZov. Odessa : ONMU, 2013. 279 s. 252 s. 
of the reliability of the system requires a detailed analytical dependence $\bar{F}_{0}(t)$ in general. Under the exponential law of distribution on failure, formula (36) can be used using a number of standard programs. Under the second laws, the transformation of the reliability function of the redundant system into an analytical form is associated with rather cumbersome transformations and calculations. To simplify this problem, dependence (36) can be represented in the form ${ }^{5}$ :

$$
\bar{F}_{n, m}(t)=\sum_{k=0}^{m}(-1)^{k} A_{k}\left[\bar{F}_{0}(t)\right]^{(n+k)}
$$

The coefficients $A_{k}$ are determined from formula (2.36) as a result of substitution $F_{0}(t)=1-\bar{F}_{0}(t)$ and reduction of similar terms. The values of these coefficients in relation to some combinations of the numbers of reserve $m$ and the main $n$ elements, characteristic, for example, for port transshipment complexes, are given in table 4.

For a system with one spare element $(m=1)$, formula (37) is simplified:

$$
\bar{F}_{n, 1}(t)=(n+1)\left[\bar{F}_{0}(t)\right]^{n}-n\left[\bar{F}_{0}(t)\right]^{(n+1)}
$$

Table 5

The value of coefficients $A_{k}$ in formula (37)

\begin{tabular}{|c|c|c|c|c|c|c|}
\hline $\mathrm{m}$ & $\mathrm{n}$ & $\mathrm{A}_{0}$ & $\mathrm{~A}_{1}$ & $\mathrm{~A}_{2}$ & $\mathrm{~A}_{3}$ & $\mathrm{~A}_{4}$ \\
\hline \multirow{4}{*}{2} & 3 & 10 & 15 & 6 & - & - \\
& 4 & 15 & 24 & 10 & - & - \\
& 5 & 21 & 35 & 15 & - & - \\
& 6 & 28 & 48 & 21 & - & - \\
\hline \multirow{3}{*}{3} & 4 & 35 & 84 & 70 & 20 & - \\
& 5 & 56 & 140 & 120 & 35 & - \\
& 6 & 84 & 216 & 189 & 56 & - \\
\hline 4 & 6 & 210 & 720 & 945 & 560 & 126 \\
\hline
\end{tabular}

As an example of the use of formula (37) and table 5 a system consisting of $\mathrm{n}=6$ main machines and $\mathrm{m}=4$ machines of the loaded reserve is considered.

Suppose that all machines have a distribution of operating time for failure according to the law of Weibull - Gnedenko:

${ }^{5}$ Zubko N. F. Nadyozhnost i planirovanie ekspluatatsii mashin: Uchebnoe posobie dlya VUZov. Odessa : ONMU, 2013. 279 s. 128 s. 


$$
F(t)=1-\exp \left(-\lambda^{p} t^{p}\right)
$$

This law is two parametric, with parameters $\lambda$ and $\mathrm{p}$. By changing the values of the parameters, it is almost always possible to obtain dependence $F_{0}(t)$, which is quite close to the statistical sample of the failure time of any mechanical system. Recall that at $\mathrm{p}=1$, distribution law (39) becomes the law of exponential distribution (sudden failures), and at $\mathrm{p}>4$ it becomes quite close to the law of normal distribution, which corresponds to the distribution of operating time relative to gradual failures with multifactorial influence.

Substituting the reliability function of one machine $\bar{F}_{0}(t)=e^{-\lambda^{p} t^{p}}$ and the corresponding coefficients from table 2 in formula (37), we find the probability function of failure-free operation of the redundant system:

$$
\bar{F}_{6,4}(t)=e^{-6 \lambda^{p} t^{p}}\left(210-720 e^{-\lambda^{p} t^{p}}+945 e^{-2 \lambda^{p} t^{p}}-560 e^{-3 \lambda^{p} t^{p}}+126 e^{-4 \lambda^{p} t^{p}}\right)
$$

Obviously, the obtained dependence allows for known values $\bar{F}_{n, m}(t)$ of $\lambda$ and $p$ to predict all the main indicators of the system reliability. Including the average operating time for failure and its variance, the intensity of failures, the probability of failure-free operation during operation $t$ and the probability of implementation of additional operation, provided that by time $t$ the system has remained operational. The values of these indicators are sufficient to solve most of the problems associated with the operation of technical devices.

Table 6 shows comparative indicators of the unreserved reliability system and redundant system with the reliability function of its elements (39) at the distribution parameters $\lambda=0.005$ and $p=2$.

The symbols in the table are:

$T_{0}, T_{6,0}, T_{6,4}$ - respectively, the average operating time for failure of one machine, not a redundant system with $\mathrm{n}=6, \mathrm{t}=0$ machines and the same system with $\mathrm{m}=4$ machines loaded reserve; $\bar{F}_{0}\left(T_{p}\right), \bar{F}_{6,0}\left(T_{p}\right), \bar{F}_{6,4}\left(T_{p}\right)-$ the probability of trouble-free operation for the estimated time $=80$ hours, respectively, one machine, not backed up and backed up systems.

The table also shows the average operating time of non-redundant $T_{6,0}\left(T_{p}\right)$ and redundant $T_{6,4}\left(T_{p}\right)$ systems for the estimated time $T_{p}$, determined by the formulas:

$$
T_{6,0}\left(T_{p}\right)=\int_{0}^{T_{p}}\left[\bar{F}_{0}(t)\right]^{6} d t \quad \text { and } \quad T_{6,4}\left(T_{p}\right)=\int_{0}^{T_{p}} \bar{F}_{6,4}(t) d t
$$


As follows from the results of the calculations given in table 5, the main indicators of the reliability of the redundant system, including the probability of implementation of the planned operating time, are quite high. However, the economic feasibility of the adopted level of redundancy of the system can be established only by estimating the criterion of optimality (32), consistently increasing the number of reserve elements $\mathrm{m}$ to reach the value of $\mathrm{maxH}$.

Table 6

\section{Comparative indicators of the unreserved reliability and redundant systems}

\begin{tabular}{|c|c|c|c|c|c|c|c|}
\hline \multicolumn{2}{|c|}{$\begin{array}{c}\text { The operating } \\
\text { time on refusal }\end{array}$} & \multicolumn{3}{c|}{$\begin{array}{c}\text { The probability of failure } \\
\text { works for Tr }\end{array}$} & \multicolumn{2}{c|}{$\begin{array}{c}\text { The operating time } \\
\text { for settlement period } \\
T p\end{array}$} \\
\hline$T_{0}$ & $T_{6,0}$ & $T_{6,4}$ & $\bar{F}_{0}\left(T_{p}\right)$ & $\bar{F}_{6,0}\left(T_{p}\right)$ & $\bar{F}_{6,4}\left(T_{p}\right)$ & $T_{6,0}\left(T_{p}\right)$ & $T_{6,4}\left(T_{p}\right)$ \\
\hline 177 & 72 & 157 & 0.852 & 0.383 & 0.991 & 60.4 & 79.9 \\
\hline
\end{tabular}

The second case. Unloaded reserve. The probability of failure-free operation of such a system, when its elements are not the same in terms of reliability, is very difficult to express through integrals such as convolutions and even the average failure time has a complex form, the calculation of which is associated with significant errors. Therefore, we limit to systems whose elements have an exponential distribution of operating time to failure with the same parameter $\lambda$. The reliability of such systems is determined by the dependence ${ }^{6}$ :

$$
\bar{F}_{n, m}(t)=e^{-n \lambda t} \sum_{k=0}^{m} \frac{(n \lambda t)^{k}}{k !}
$$

Then the problem is solved by substituting reliability function (42) with the equivalent value of $\lambda$ in the formula of optimality criterion (6.39) and replacing the hourly income from the use of machines in the loaded reserve $\left(c_{\partial p}-c_{e p}\right)$ losses (with a minus sign) for 1 hour of downtime in the unloaded reserve $\left(-c_{\mu p}\right)$, as shown in example 3 .

\section{Example of calculation 3.}

Output data. Let us calculate the optimal reserve of a group of mooring gantry cranes, which are used in a simplified version of the "warehouse-ship". Cargo - coal; a vessel with a carrying capacity of $Q=75,000$ tons; rate of parking time of the vessel under cargo operations $T_{H}=40 \mathrm{~h}$; technological

${ }^{6}$ Bao Qifan. Research and development of automatic bulk cargo equipment in modern parts. Port Technology International, 2009. Vol. 41. Pp. 88-93. 
productivity of the crane $\mathrm{q}=500 \mathrm{t} / \mathrm{h}$. The remaining indicators correspond to table 3.

All cranes have the same reliability function according to WeibullGnidenko law:

$$
\bar{F}_{0}(t)=\exp \left(-0.005^{2} t^{2}\right)
$$

The average operating time of the crane to failure is:

$$
T_{0}=\frac{1}{0.005} \Gamma\left(1+\frac{1}{2}\right)=178 \mathrm{~m}-\text { year }
$$

\section{The results of the calculation.}

The minimum required number of cranes for the implementation of work during the standard time (6.35):

$$
n=75000 / 500 \cdot 40=3.75 \text { units. }
$$

We accept the maximum allowable number of machines in terms of technological conditions when unloading the vessel $n=4$ units. The estimated calendar time of technological processing of the vessel $T_{p}=37.5$ hours. Since $T p<T_{H}$, a bonus is possible for reducing the parking time of the vessel.

The first case. Loaded reserve. To calculate the reliability function of the redundant system, the formula (37) and table 4 are used. The obtained analytical dependences are presented in table 7.

The probability of failure-free operation (2.36) the values $\bar{F}_{4, m}\left(T_{P}\right)$ of the average operating time of the system $T_{4, m}\left(T_{P}\right),(31)$ and the total residence time of reserve machines in reserve state $T_{c m}(m)$ (33) for the estimated time at different levels of redundancy are given in table 6 .

We rewrite the criterion of optimality (2.32) in relation to the initial data of the problem:

$$
\begin{gathered}
\max H=\max 4(1250-100) T_{\partial}+\left\{\begin{array}{ll}
\left(40-T_{\partial}\right) 1200, & T_{\partial}<40 \\
\left(40-T_{\partial}\right) 2400, & T_{\partial}>40
\end{array}\right\}+ \\
+(400-200) T_{m p}
\end{gathered}
$$

The results of calculations by formula (44) taking into account the data in table 6 are given in table 8 .

As follows from table 8 already in the presence of one reserve crane the probability of performance of estimated time of works is high enough. 
Reliability functions of the redundant system with $n=4$ main and $t$ reserve elements

\begin{tabular}{|c|c|}
\hline $\mathrm{m}$ & Reliability function $\bar{F}_{4, m}(t)$ \\
\hline 0 & {$\left[e^{-0.005^{2} t^{2}}\right]^{4}$} \\
\hline 1 & $5\left[e^{-0.005^{2} t^{2}}\right]^{4}-4\left[e^{-0.005^{2} t^{2}}\right]^{5}$ \\
\hline 2 & $15\left[e^{-0.005^{2} t^{2}}\right]^{4}-24\left[e^{-0.005^{2} t^{2}}\right]^{5}+10\left[e^{-0.005^{2} t^{2}}\right]^{6}$ \\
\hline 3 & $35\left[e^{-0.005^{2} t^{2}}\right]^{4}-84\left[e^{-0.005^{2} t^{2}}\right]^{5}+70\left[e^{-0.005^{2} t^{2}}\right]^{6}-20\left[e^{-0.005^{2} t^{2}}\right]^{7}$ \\
\hline
\end{tabular}

As shown by the results of the calculations given in table. 7 the maximum increase in profit corresponds to the value of $t=1$ unit:

$$
\Delta \mathrm{H}=363700-345500=18200 \mathrm{USD}
$$

Table 8

Indicators of the system reliability with different levels of redundancy

\begin{tabular}{|c|l|l|l|l|}
\hline$m$ (res.mach.) & 0 & 1 & 2 & 3 \\
\hline $\bar{F}_{4, m}\left(T_{P}\right)$ & 0.783 & 0.969 & 0.996 & 1 \\
\hline$T_{4, m}\left(T_{P}\right)$ & 34,65 & 37,25 & 37,48 & 37,5 \\
\hline$T_{c m}(m)$ & - & 34,65 & 71,9 & 109,4 \\
\hline
\end{tabular}

Table 9

The results of calculations of profit $\mathbf{H}(\mathrm{m})$ obtained during the processing period of the main object, depending on the level of provisioning

\begin{tabular}{|c|c|c|c|c|}
\hline $\begin{array}{c}\mathrm{m} \\
\text { (res. mach. }\end{array}$ & 0 & 1 & 2 & 3 \\
\hline$H(m)$ USD & 345500 & 363700 & 365300 & 365400 \\
\hline
\end{tabular}

That is, as a backup is enough to allocate one crane, in addition to the minimum required. However, when operation in the reserve of the second crane is not very important, it is expedient to use it also as a reserve.

The second case. Unloaded reserve. The calculations are performed in relation to the optimality criterion in form (44) taking into account the reliability function of the system (42). 
The problem statement and initial data are the same as in the case of a loaded reserve. Cranes have an exponential distribution of operating time to failure:

$$
F(t)=e^{-0.0066 \cdot t} .
$$

The results of the calculations are given in table 10 .

As follows from the data of table 8 apparently the best is the level of redundancy at $m=2$. The profit is quite high. The standard parking time of the vessel $T_{H}=40$ hours is practically fulfilled. Keeping more than 2 cranes in an unloaded reserve does not lead to a significant increase in profits.

Table 10

The results of profit calculations $H(\mathrm{~m})$ with unloaded reserve

\begin{tabular}{|c|c|c|c|c|}
\hline $\mathrm{m}$ & 0 & 1 & 2 & 3 \\
\hline $\bar{F}_{4, m}(t=40)$ & 0,372 & 0,739 & 0,922 & 0,982 \\
\hline $\mathrm{T}_{4, \mathrm{~m}}\left(\mathrm{~T}_{\mathrm{p}}\right)$ год & 23,8 & 33,7 & 36,6 & 37,3 \\
\hline $\mathrm{T}_{\mathrm{cт}}(\mathrm{T})$ год & - & 23,8 & 57,5 & 94,1 \\
\hline $\mathrm{H}(\mathrm{m})$ г.о. & 267400 & 336100 & 354100 & 355500 \\
\hline
\end{tabular}

\section{The end of the example}

\section{CONCLUSIONS}

The methods of forecasting reliability indicators and indicators of operational states of a group of machines of the reloading complex as a restorative system of sliding redundancy for the given conditions of their technological use are offered. The methods for solving problems of optimizing the level of redundancy, both for the recovery and non-recovery group of machines are provided.

The obtained results make it possible to predict the quality of operation of this system in the process of implementation of planned work and quickly improve its parameters in terms of the level of redundancy and capacity of the next repair service.

\section{SUMMARY}

The mathematical model for predicting the operational condition of reloading machines for the set conditions of their technological use is presented. The system of sliding redundancy consisting of identical machines with restoration in the stationary period of operation is considered. (Therefore, in this problem...4th line above fig. 2.1) The algorithms for calculating the main indicators of reliability, performance indicators and methods for solving 
problems of optimizing the level of redundancy of a group of machines as a single renewable and non-renewable system in the process of implementing the planned scope of work are given. The examples of calculations of the named indicators of quality of the system and optimum level of its redundancy for the basic settlement variants are shown.

\section{REFERENCES}

1. Gnedenko B. V., Belyaev Yu. K, Solovev A. D. Matematicheskie metodyi v teorii nadezhnosti. M.; Nauka, 1965. $524 \mathrm{~s}$.

2. Zubko N. F. Nadyozhnost i planirovanie ekspluatatsii mashin: Uchebnoe posobie dlya VUZov. Odessa: ONMU. 2013. 279 s.

3. Nadyozhnost tehnicheskih sistem: Spravochnik / Yu. K. Belyaev, V. A. Bogatyirev, V. V. Bolotin i dr.; Pod red. I. A. Ushakova. M.: Radio i svyaz, $1985.608 \mathrm{~s}$.

Information about the authors:

Zubko M. F.,

Candidate of Technical Sciences, Professor, Professor at the Department of Lifting and Transport Machines and Engineering of Port Technological Equipment,

Odessa National Maritime University

34, Mechnikov str., Odessa, 65029, Ukraine ORCID ID: orcid.org/0000-0003-4826-5895

Nemchuk O. O., $\mathrm{PhD}$, Vice-Rector of Science, Corresponding Member of the Transport Academy of Ukraine, Full Member of Lifting Transport Academy of science of Ukraine, Odessa National Maritime University 34, Mechnikov str., Odessa, 65029, Ukraine ORCID ID: orcid.org/0000-0001-5633-8930 